\title{
Membrane Trafficking Components in Cytokinesis
}

\author{
Bor Luen Tang ${ }^{a, b}$
}

aDepartment of Biochemistry, Yong Loo Lin School of Medicine, National University Health System;bNUS Graduate School of Integrative Sciences and Engineering, National University of Singapore, 8 Medical Drive, Singapore

\section{Key Words}

Cytokinesis $\cdot$ Exocyst $\cdot$ Membrane trafficking $\bullet$ Rab

\begin{abstract}
Cytokinesis, the last major step of cell division, is a complex multistage process involving specific rearrangement of cellular cytoskeleton and a flurry of vesicular transport activities at the cell division plane. Vesicular traffic from the exocytic pathway and the endocytic/recycling pathway, operating again after being shut down since prophase, are engaged to supply the mitotic midzone with materials that would facilitate furrowing, midbody thinning and subsequent abscission of daughter cells. Cytokinesis is spatial and temporally regulated by mitotic kinases, and involves modulation by Arf and Rab small GTPases and their effectors. The latter include vesicle targeting and tethering molecules such as motor proteins, tethering complexes and SNAREs. The process of abscission requires the ultimate engagement of endosomal sorting complex required for transport (ESCRT) complexes. Although a good deal of details remains to be deciphered, cytokinesis in eukaryotes could essentially be visualized as a specialized cellular event requiring complex spatial and temporal regulated processes of membrane traffic.
\end{abstract}




\section{Introduction}

At the end of mitosis, a dividing cell undergoes cytokinesis, a process that is tightly regulated spatially and temporally to ensure proper segregation of chromosomal and cytoplasmic content to both daughter cells. For cell wall-bearing plants, cytokinesis is mediated by a microtubule and actin-based specialized platform, the phragmoplast [1], Membrane vesicles were transported to the cell division plane to form the cell plate [2], which begin as a tubulovesicular network generated by homotypic fusion of these vesicles, that subsequently grows into a farnestrated membrane sheet. The cell plate growth eventually reaches the cell cortex, where it fuses with the plasma membrane.

Animal cells, on the other hand, do not appear to generate a cell plate equivalent structure during cytokinesis. As mitosis progresses from anaphase to telophase, the overlapping of microtubules emanating from each poles at the centre of the mitotic spindle forms the spindle midzone. Actin filaments and the actin motor myosin II (actomyosin) accumulate in telophase to form a contractile ring at the plane of division [3]. This contractile actomyosin ring is attached to the plasma membrane, and its activity drives the formation of a cleavage furrow. Completed cleavage furrow ingression leaves the daughter cells connected by a thin cytoplasmic bridge densely packed with cytoskeletal structures [4]. Assembled from condensed, antiparallelly positioned microtubules and many other associated proteins, this intercellular bridge or midbody will gradually thin until the final abscission of the daughter cells occurs. The midbody acts as the platform whereby an membrane abscission machinery is assembled, which then executes the final cleavage of this intercellular bridge.

Cytokinesis requires extensive and tightly regulated membrane vesicle trafficking and targeting activities, both to, and from, the cleavage furrow. During the most part of mitosis in animal cells, exocytic membrane traffic, particularly from the endoplasmic reticulum (ER) to the Golgi apparatus, is shut down [5]. One way how this shutdown is known to occur in animal cells is via the phosphorylation of a trafficking component, p47, by Cdk1/Cdc2 [6]. Furthermore, key membrane compartments of the pathway, such as the Golgi apparatus, are fragmented to allow their equivalent inheritance by the daughter cells [7]. This fragmentation is also mediated by the phosphorylation of proteins that maintains the integrity of the Golgi stack, such as GM130 [8] and Golgi reassembly stacking protein of 65 kDa (GRASP65) [9] by mitotic kinases. Endocytic membrane traffic was also shown to be inhibited or at least temporarily attenuated during the early phase of mitosis [10-12], while endosomal to plasma membrane recycling is likewise greatly diminished [13].

Both the exocytic and endocytic/recycling pathway activities, which recovered during telophase, are both involved in cytokinesis. A wide range of components of the membrane trafficking machinery, including Rab/Arf small GTPases [14], tethering complexes [15], $\mathrm{N}$-ethylmaleimide-sensitive fusion protein (NSF)-attachment protein receptors (SNAREs) [16] and the endosomal sorting complex required for transport (ESCRT) complexes [17], have all been implicated in the cytokinesis $[18,19]$. The paragraphs below discuss the involvement of the eukaryotic membrane trafficking machinery and their known roles in this final act of cell division, with a focus on animal cells, and with analogous processes in invertebrate and plant cytokinesis also mentioned where relevant.

\section{Spatiotemporal regulation of cleavage furrow and midbody formation}

During the initiation of cytokinesis at telophase, organized positioning of microtubules in anti-parallel arrays forms an anchor for cleavage furrow formation, with subsequent furrowing mediated by the contractile actomyosin ring assembled [20]. Both the dynamics of furrowing midbody formation and its function are influence by the mitotic kinases, directly or indirectly. In general, disruption of cyclin B and inactivation of the mitotic kinase Cdk1cyclin B by the anaphase promoting complex/cyclosome (APC/C) [21] precedes cytokinesis [22]. Polo-like kinase 1 (Plk1) regulates multiple aspects of mitosis [23], and its functions 
in cytokinesis include the regulation of cyclin B destruction by APC/C, as well as other substrates more directly involved in the various steps leading up to the final abscission [24]. The initiation of cytokinesis is regulated temporally and spatially at the midbody, where key components for the process such as the protein regulating cytokinesis 1 (PRC-1), the centralspindlin complex (which contains the Rho family GTPase activating protein Cyk-4/ MgcRacGAP and the mitotic kinesin-like protein 1, MKLP1) and Plk1 are recruited. PRC1, a microtubule binding protein that could facilitate anti-parallel microtubule cross linking [25], is a Cdk substrate [26]. Transport of PRC1 to the spindle by the kinesin motor Kif4 was indeed shown to be essential for both midzone formation and cytokinesis [27].

Interestingly, while Cdk1 activity controls the docking of Plk1 onto PRC1 from the centrosomes during metaphase, Plk1 creates its own docking site on PRC1 at the central spindle at the midbody during anaphase [28]. Plk1 phosphorylates components of the centralspindlin complex and facilitates recruitment of the RhoA guanine nucleotide-exchange factor (GEF), the epithelial cell transforming sequence 2 (ECT2). The latter could itself be phosphorylated by Plk1 in vitro [29]. Plk1 can also phosphorylate other GEFs to regulate RhoA activity, as well as phosphorylating its downstream effector Rho dependent kinase 2 (ROCK2) [30]. Inhibition of Cdk1 1 by specific inhibitors could aberrantly induce cytokinesis without chromosome segregation in an ECT2 and MgcRacGAP-dependent manner [31]. The intricate interconnections between Cdk1, Plk1 and components of the midbody have yet to be fully worked out. However, what is now known attests to the notion that Cdk1 and Plk1 orchestrate the formation and functionality of the machinery required for furrowing and subsequent steps in cytokinesis.

\section{Regulation of membrane traffic during cytokinesis - the small GTPases and their effectors}

Cytokinesis requires extensive and highly regulated membrane vesicle trafficking and targeting activities, both to, and from, the cleavage furrow. Membrane trafficking is required for midzone delivery of cytoskeletal and regulatory molecules (eg. the Rho GTPases and their interacting partners) during its earlier phase [32], as well as components of the membrane abscission machinery during its later phase [33]. Exocytic traffic is clearly essential, and secretory vesicles marked by exocytic cargoes have been demonstrated to move towards the midbody in both an asymmetric [34] as well as a symmetric [35] manner from the forming daughter cells. However, endocytic and recycling traffic play equally important, nonredundant roles in this regard [36, 37] (Fig. 1A).

A role in cytokinesis has been implicated for several membrane traffic modulating members of the Rab small GTPases family. In Arabidopsis, Rab-A2 and Rab-A3 that are localized to a post-Golgi compartment are both important for cell plate formation [38]. A role for the recycling endosomes in cytokinesis in animal cells was first gleaned from observations that the recycling endosome-associated Rab11 and its interacting effector molecule nuclear fallout (nuf) are required for cell division in Drosophila embryos [39]. In mammalian cells, the nuf orthologue, Rab11-family interacting protein 3 (Rab11-FIP3) [40], which appears pericentrosomal in interphase cells, accumulates together with Rab11 at the cleavage furrow during cytokinesis [41] and functions to deliver recycling endosome materials the cleavage furrow [37]. Targeting of FIP3 per se to the midbody, however, appeared independent of Rab11 activity [37]. Interestingly, FIP3 is a phosphoprotein, and its phosphorylation status appears to be cell cycle-regulated. One of its phophorylation sites (Ser102) is a target of Cdk1 in vitro [42]. Ser102 is phosphorylated in metaphase, but is dephosphorylated as cells enter telophase, an observation which correlated with Rab11-FIP3's translocation from the cytosol to membranes during telophase.

Members of the Arf and Rab small GTPases act as molecular switches, and in their GTP-bound, active state, engages effectors that modulate membrane dynamics. Both Rab11FIP3 and another Rab11 effector, Rab11-FIP4, interact with the Arf family member of small 


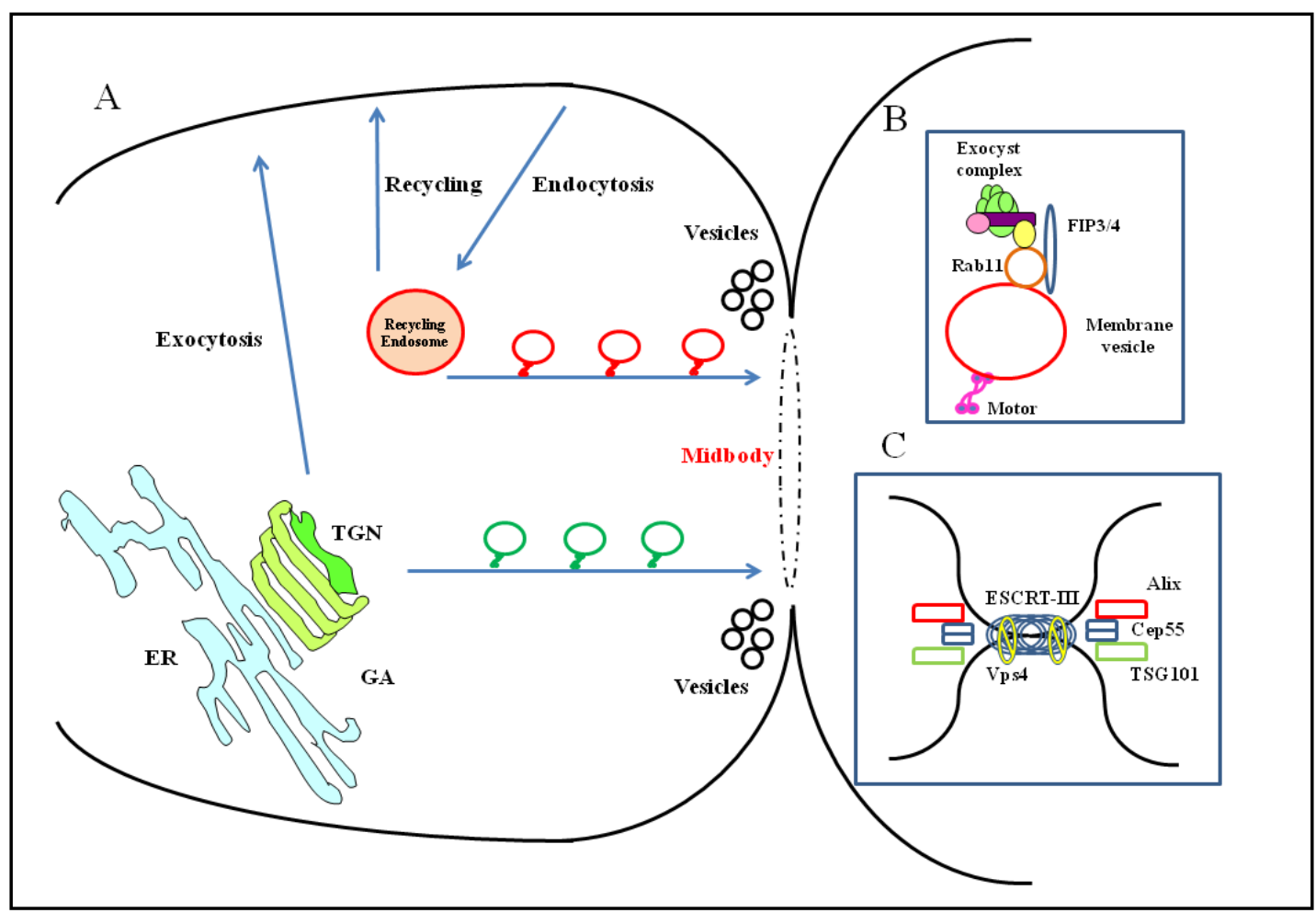

Fig. 1. A schematic diagram depicting membrane traffic processes and components required for cytokinesis in animal cells. A) Both exocytic and endocytic/recycling pathways are engaged in vesicle traffic to the midbody during cytokinesis. ER - endoplasmic reticulum, GA - Golgi apparatus, TGN- trans-Golgi network. B) A transport vesicle/carrier decorated by Rab11 and engaging effectors such as exocyst and Rab11 family interacting proteins (FIPs). C) Abscission machinery components engaged in the final steps of cytokinesis. Alix - ALG-2-interacting protein X, Cep55 - centrosome protein of $55 \mathrm{kDa}$, ESCRT - endosomal sorting complex required for transport, TSG100 - tumor susceptibility gene 101, Vps4 - vacuolar protein sorting 4.

GTPase that is involved in post-Golgi traffic, namely Arf6. The latter's roles in endocytosis and endocytic recycling are well known [43]. Arf6 could be localized to the cleavage furrow region, and a ternary complex formed between both the Rab11-FIPs and Rab11-Arf6 could be detected [44]. Another more recently uncovered role for Arf6 in cell division pertains to its ability to stabilise the midbody by interacting with the centralspindlin complex, which is essential for the formation of microtubule bundle structures of the midbody. Centralspindlin assembles in a sharp band at the centre of the midbody, and this concentrated localization could be disrupted by 14-3-3 proteins [45]. ARF6 appears to preserve midbody structural integrity by competing with 14-3-3 for binding to centralspindlin [46].

Another Rab family member known to function in cytokinesis is Rab35 [47]. Rab35 is known to regulate endocytic recycling [48], and has distinct actin-modulating activities [49, 50]. One of the key processes occurring at the cleavage furrow is modulation of actin dynamics. Rab11 and Arf6-controlled Rab11-FIP3/nuf apparently act in this regard by promoting actin polymerization [51,52]. Rab35 and its effectors with known actin-modifying activity such as fascin [49] are likely to act in the same vein. Another recently described Rab35 effector in connection with cytokineis is the protein mutated in Oculocerebrorenal Syndrome of Lowe (OCRL), a phosphatidylinositol-4,5-bisphosphate (PtdIns(4,5)P2) 5-phosphatase named OCRL-1 [53]. Rab35 binds OCRL-1 and regulates its localization at the intercellular bridge, and silencing of either molecule inhibits abscission, with the dividing cell accumulating abnormal amounts of PtdIns(4,5)P2 and F-actin at the midbody [54]. This is a defect that is also manifested by cell lines derived from Lowe Syndrome patients. As previous genetic 
analysis in Drosophila have demonstrated PtdIns(4,5)P2's function at the cleavage furrow [55], this finding further strengthened the notion that is important for normal cytokinesis. In fact, a number of other aspects of phosphoinositide metabolism are also important for cytokinesis. It was shown in Drosophila spermatocytes that the phosphatidylinositol (PI) 4-kinase III $\beta$ gene product four wheel drive $(F w d)$ is key for the formation of PI4P-containing secretory carriers and Rab11 localization to the midzone [56].

There appears to be a complex interplay of feedback regulations between the small GTPase involved in cytokinesis. As mentioned above, Rab11 and Arf6 could both regulate the same subset of effector. Recent findings have now revealed an intricate reciprocal regulation of activities between Rab35 and Arf6. Rab35 may modulate Arf6 activity, as its effector centaurin- $\beta 2$, acting as an Arf6-GTPase-activating protein (GAP), has been recognized in Rab35's particular role in modulating neurite outrowth [57]. Conversely, Arf6 activity could in turn influence Rab35 function, as the Rab35 GAP EPI64B is also an effector of Arf6 [58].

During mitosis, animal cells' adherence to the substratum, at least in culture, appeared somewhat impaired as mitotic cells commonly adopt a rounded appearance. Cell adhesion however, is critical for cytokinesis at least in some contexts. For example, unanchored fibroblasts could not complete cytokinesis unless augmented by oncogenic signals [59]. The focal adhesion complex and its components have also been shown to be important for cytokinesis. Disruptions of talin A could detach the actomyosin contractile ring from the cell membrane, and result in concomitant regression of the cleavage furrow [60]. Integrins, a key cell adhesion molecule family, is known to be important for mitotic spindle positioning and orientation [61]. An interesting finding relating integrins to cytokinesis is that proper endocytosis and recycling of intergrins is required for the process, and that this is regulated by Rab21 [62]. Chromosomal deletion and loss of Rab21 gene expression is manifested by some cancer cells, and re-expression of Rab21 reversed a "multinuclear" phenotype exhibited by these. Abnormal integrin traffic was also linked with the generation of aneuploidy and cell transformation in vitro and in vivo, while downregulation of Rab21 correlates with increased malignancy in human prostate and ovarian cancer samples [63].

\section{Membrane tethers and motor proteins in cytokinesis}

Other than the Rab11-FIPs, another key effector that is engaged by Rab11 and Arf6 in cytokinesis is the exocyst complex (Fig. 1B), which has a well known, more general role in various forms of polarized exocytosis ranging from yeast budding to neurite outgrowth [64]. The exocyst component Exo70p co-immunoprecipitates both Rab11-FIP3 and Rab11FIP4, and silencing of Exo70p leads to impaired cytokinesis and dislocalization of Rab11 and Rab11-FIP3 from the midbody [44]. Exocyst function in cytokinesis is important for cellularization of Drosophila embryo [65], and cell plate maturation in plants [66]. The Ral GTPases (RalA and RalB) that have been heavily implicated in tumorigenesis [67] are also known principal regulators of exocyst activity. It is thus not surprising that this pair of small GTPases also have apparent roles in cytokinesis $[68,69]$. The midbody protein centriolin interacts with both the membrane tethering exocyst complex and the SNARE complexes required for the actual vesicle fusion step (see below), and may serve to regulate membrane vesicle docking/fusion processes in cytokinesis [34].

The exocyst belongs to a functionally defined class of multiprotein complexes that act in tethering of transport vesicles or membranous carriers to target membrane prior to fusion $[70,71]$. Other than the exocyst, the Transport Protein Particle (TRAPP) II complex $[72,73]$ has also been implicated in cytokinesis. Mutations in the Drosophilla gene brunelleschi (bru), the orthologue of the yeast Trs120p subunit of TRAPPII, resulted in failed furrow ingression in male meiotic cells, and localization of dRab11 to the cleavage furrow requires functional bru [74]. The TRAPPII complex was also shown to be required for cytokinesis in Arabidopsis [75]. In the AtTRS120 mutants, vesicles accumulated at the equator of dividing cells, but failed to assemble into a cell plate. 
Other than actin modulators and the membrane tethering complexes, another type of effector logically expected to be engaged by the small GTPases in vesicle transport during cytokinesis would be microtubule-based motor proteins and/or their adaptors. Indeed, the c-jun N-terminal kinase (JNK)-interacting proteins 3 and 4 (JIP3 and JIP4), which are adaptors of kinesin-1 and dynactin complex, are both effectors of Arf6 [76]. Binding of activated Arf6 to the second leucine zipper domain of JIP3 and JIP4 attenuates association with kinesin-1, but enhanced JIPs' interactions with the dynactin complex. The interactions between Arf6, JIPs, kinesin-1, and the dynactin complex therefore control the trafficking of recycling endosomes to and from of the midbody structure [76].

\section{SNAREs and vesicle fusion in cytokinesis}

As mentioned above, vesicles derived from both the exocytic and endocytic pathways contributed to the formation of the cell plate in plants. Cell plate formation definitely requires vesicle fusion, which is mediated by SNAREs and their regulators [77]. The syntaxin-like molecule KNOLLE [78] has been long recognized as a target membrane ( $\mathrm{t}$ )-SNARE protein critical for cytokinesis and cell plate formation in plants. KNOLLE interacts with the Sec1-like KEULE [79], and another t-SNARE, which is the neuronal SNAP25 homologue AtSNAP33 [80]. An association with cytokinesis has also been reported for another SNARE-like molecule, NPSN11 [81]. Although the exact SNARE complex (or complexes) involved are not yet clear, possible cognate vesicle (v)-SNARE partners to the t-SNAREs above, namely VAMP721 and VAMP722, have recently been reported [82]. Plant cytokinesis may also involve another membrane fusion factor, namely the AAA-ATPase Cdc48p/p97, engaging alternative SNAREs such as the plant homologue of animal syntaxin 5, SYP31 [83].

The exact role of vesicle fusion in animal cell cytokinesis is less clear. Membrane vesicles move to and from the midbody, but towards the later part after furrow formation, there is an accumulation of vesicles at the midbody. While furrow formation does not appear to require SNARE-mediated fusion per se in mammalian cells, the subsequent abscission process does appear to require the t-SNARE syntaxin 2 and the v-SNARE VAMP8/endobrevin [84]. In Drosophila, a hypomorphic allele of the Drosophila syntaxin 5 homologue, dSyx5 led to a phenotype of germ cells failing to complete cytokinesis, and defects in spermatid elongation and maturation [85]. However, in this case it is unclear if the role of dSyx5 is specific, as disruption of Golgi-localized syntaxin 5 is likely to also cause a general disruption of Golgi traffic. Another animal SNARE that has been implicated in cytokinesis is syntaxin 16, a TGNlocalized SNARE that could be recruited to the midzone and midbody [86].

The exact mechanistic role for SNAREs in cytokinesis in animal cells has not yet been resolved. In general, while there clearly is fusion between vesicles targeted and the plasma membrane at the midbody, it is unclear what roles these fusions serve, and how these fusions might impact on, or may indeed be required for, the final abscission step. Vesicle targeting and accumulation at the midbody may aid abscission by facilitating the gradual thinning the midbody, or may simply serve to deliver components of the abscission apparatus.

\section{Abscission and the role of endosomal sorting complex required for transport III (ESCRT-III)}

The final resolution of the midbody and separation of daughter cells [3] requires various vesicle tethering complexes describe above [87] as well as ESCRT-III, which likely serve the role in executing the final scission $[33,88]$. The ESCRT complexes 0, I, II, and III play critical roles in topologically equivalent membrane processes of multivesicular body (MVB) biogenesis, enveloped virus budding, as well as cytokinesis [89, 17]. ESCRT-I and ESCRT-II direct membrane budding in an "unconventional" manner, (away from the cytosol) while ESCRT-III cleaves these bud from their cytosolic faces [89]. Different processes involving 
ESCRT utilize divergent pathways that lead to ESCRT-III assembly within the neck of a bud structure, ultimately resulting in membrane separation [90]. ESCRT-III-mediated membrane neck cleavage as a generic mechanism is now known to be crucial for many cellular processes, including receptor signalling, autophagy, establishment of cell polarity, cell migration, and even mRNA transport [91].

ESCRT-III in animal cells is composed of a number of homologous proteins grouped under charged multivesicular body proteins 1-7 (CHMP1-7), and the increased sodium tolerance-1 (IST1) protein $[89,92]$. In a recruitment order established for the yeast complex, CHMP6 is first recruited by ESCRT-II to nucleate the assembly of two CHMP4. These are capped by CHMP3 and CHMP2s, which in turn recruits an ATPase, Vps4 [93], to catalyze eventual disassembly of ESCRT-III and recycling of components. A requirement for the ESCRT machinery in cytokinesis was first noted when the tumor susceptibility gene 101 (TSG101), a subunit of ESCRT-I, and ALG-2-interacting protein X (Alix), an ESCRT-associated protein, were apparently recruited to the midbody during cytokinesis by centrosome protein of $55 \mathrm{kDa}$ (Cep55) [94] (Fig. 1C). CEP55 resides at the centrosome through most part of the cell cycle, but then migrates to the midbody at the start of cytokinesis, and its action there is required for abscission. Interestingly, CEP55 is a substrate for both Cdk1 and Plk1 [95]. Upon mitotic entry, centrosome dissociation of Cep55 is triggered by Erk2/Cdk1dependent phosphorylation at Ser425 and Ser428. Ser425/428 phosphorylation is required for CEP55's interaction with Plk1, which phosphorylates Cep55 at Ser436. Phosphorylationdeficient mutant forms of Cep55 caused defective cytokinesis. The relocation of Cep55 from the centrosome to the midbody is therefore regulated by the mitotic kinases to function in the final steps of cytokinesis.

TSG101 and the Alix compete for binding to the ESCRT and Alix-binding region (EABR) of CEP55 [96]. Live-imaging analysis indicated that TSG101 and CHMP4B are sequentially recruited to the midbody, forming a series of cortical rings [97]. Both CHMP4B and the ESCRT disassembly factor Vps4 is recruited to the narrow constriction site where abscission occurs late in cytokinesis, often immediately preceding cell separation. This precise correlation in time and exact spatial location of ESCRT-III and Vps4 with abscission suggests that these complexes play a direct role in abscission. A separate report has also implicated yet another ESCRT-III subunit, CHMP4C, in abscission timing [88]. CHMP4C functions in the Aurora B kinase-dependent abscission checkpoint [98] to prevent premature abscission of intercellular chromosome bridges and accumulation of DNA damage. The ESCRT machinery may therefore protect against genetic damage by coordinating midbody abscission with the abscission checkpoint.

Exactly how ESCRT-III executes abscission is not yet completely understood. Tantalizing clues has recently came from high resolution electron tomography of the midbody undergoing abscission, which revealed helical structures made up filaments of $~ 17-n m$ in diameter [99]. These appeared to constrict the intercellular membrane bridge into to a single stalk. ESCRTIII co-localized with the constriction zones and was apparently required for the assembly of these filaments. Components of ESCRT-III are known to polymerize into various filamentous and tubular structures [100-102], and spiral-shaped ESCRT-III filaments, in the context of MVB formation or viral budding, assemble around the neck of the forming vesicle to result in abscission. It is therefore plausible that ESCRT-III-based filaments, positioned perpendicular to the microtubules parallel to the midbody, could potentially generate the contractile force necessary to drive membrane deformation and initiate midbody abscission [33]. Future work would be required to reveal the mechanistic details of the final abscission step.

\section{Epilogue}

Recent findings have begun to shed some light on the cellular and molecular events that occur during the final stages of cell division, leading up the complete physical separation of daughter cells. Of note, it is clear that vesicular traffic from both the exocytic and the endocytic 
pathways is involved, and vesicular membrane transport delivers fresh membrane lipids as well as protein components required for cytokinesis. Membrane vesicle (or carrier) delivery and fusion is regulated by Arf/Rab GTPases, and mediated by their effectors (motors, tethering factors) as well as SNARE proteins, with the final abscission step involving ESCRTIII.

Amongst the issues that have remained unresolved is a description, in sufficient detail, of the succession of steps that occurs at the midbody leading to abscission. The intricate and complex reciprocal interplay between Rab11, Arf6 and Rab35 aside, the exact roles of their effectors, the order of their functions, and the link to abscission are also not yet clear. In this regard, a very recent finding of a functional interaction between Rab11-FIP4 and TSG101 could connect Rab11-controlled processes and components of the ESCRT pathway [103]. Other questions that remained include what are the nature of vesicles observed to accumulate at the midbody in late telophase, and how exactly do these fuse eventually (and with which membrane). Pertaining to abscission, how exactly does ESCRT-III mediate the final abscission, and how is this final step timed in relation to preceding events requires some resolution. A textbook-like description with some degree of molecular and structural clarity of cytokinesis may require breakthroughs in super-resolution imaging, as well as molecular tools (mutants, inhibitors) to visualize various steps arrested or morphologically frozen at particular steps at the ultrastructural level.

\section{Acknowledgements}

Work is supported by the NUS Graduate School of Integrative Sciences and Engineering. The author declares no competing interests.

\section{References}

1 Van Damme D, Inzé D, Russinova E: Vesicle trafficking during somatic cytokinesis. Plant Physiol 2008;147:1544-1552.

-2 Seguí-Simarro JM, Austin JR, White EA, Staehelin LA: Electron tomographic analysis of somatic cell plate formation in meristematic cells of Arabidopsis preserved by high-pressure freezing. Plant Cell 2004;16:836856.

- Glotzer M: The molecular requirements for cytokinesis. Science 2005;307:1735-1739.

4 Elad N, Abramovitch S, Sabanay H, Medalia O: Microtubule organization in the final stages of cytokinesis as revealed by cryo-electron tomography. J Cell Sci 2011;124:207-215.

5 Featherstone C, Griffiths G, Warren G: Newly synthesized G protein of vesicular stomatitis virus is not transported to the Golgi complex in mitotic cells. J Cell Biol 1985;101:2036-2046.

6 Kano F, Tanaka AR, Yamauchi S, Kondo H, Murata M: Cdc2 kinase-dependent disassembly of endoplasmic reticulum (ER) exit sites inhibits ER-to-Golgi vesicular transport during mitosis. Mol Biol Cell 2004;15:42894298.

7 Persico A, Cervigni RI, Barretta ML, Colanzi A: Mitotic inheritance of the Golgi complex. FEBS Lett 2009;583:3857-3862.

-8 Lowe M, Rabouille C, Nakamura N, Watson R, Jackman M, Jämsä E, Rahman D, Pappin DJ, Warren G: Cdc2 kinase directly phosphorylates the cis-Golgi matrix protein GM130 and is required for Golgi fragmentation in mitosis. Cell 1998;94:783-793.

-9 Wang Y, Seemann J, Pypaert M, Shorter J, Warren G: A direct role for GRASP65 as a mitotically regulated Golgi stacking factor. EMBO J 2003;22:3279-3290.

$>10$ Berlin RD, Oliver JM, Walter RJ: Surface functions during Mitosis I: phagocytosis, pinocytosis and mobility of surface-bound Con A. Cell 1978;15:327-341.

11 Boucrot E, Kirchhausen T: Endosomal recycling controls plasma membrane area during mitosis. Proc Natl Acad Sci USA 2007;104:7939-7944. 
12 Fielding AB, Willox AK, Okeke E, Royle SJ: Clathrin-mediated endocytosis is inhibited during mitosis. Proc Natl Acad Sci USA 2012;109:6572-6577.

13 Warren G, Davoust J, Cockcroft A: Recycling of transferrin receptors in A431 cells is inhibited during mitosis. EMBO J 1984;3:2217-2225.

14 Itzen A, Goody RS: GTPases involved in vesicular trafficking: structures and mechanisms. Semin Cell Dev Biol 2011;22:48-56.

15 Bröcker C, Engelbrecht-Vandré S, Ungermann C: Multisubunit tethering complexes and their role in membrane fusion. Curr Biol 2010;20:R943-R952.

16 Jahn R, Scheller RH: SNAREs--engines for membrane fusion. Nat Rev Mol Cell Biol 2006;7:631-643.

$>17$ Henne WM, Buchkovich NJ, Emr SD: The ESCRT pathway. Dev Cell 2011;21:77-91.

-18 Prekeris R, Gould GW: Breaking up is hard to do - membrane traffic in cytokinesis. J Cell Sci 2008;121:15691576.

19 Neto H, Collins LL, Gould GW: Vesicle trafficking and membrane remodelling in cytokinesis. Biochem J 2011;437:13-24.

20 D'Avino PP, Savoian MS, Glover DM: Cleavage furrow formation and ingression during animal cytokinesis: a microtubule legacy. J Cell Sci 2005;118:1549-1558.

21 Peters JM: The anaphase-promoting complex: proteolysis in mitosis and beyond. Mol Cell 2002;9:931-943.

22 Wheatley SP, Hinchcliffe EH, Glotzer M, Hyman AA, Sluder G, Wang YL: CDK1 inactivation regulates anaphase spindle dynamics and cytokinesis in vivo. J Cell Biol 1997;138:385-393.

-23 Nigg EA: Polo-like kinases: positive regulators of cell division from start to finish. Curr Opin Cell Biol 1998;10:776-783.

24 Petronczki M, Lénárt P, Peters JM: Polo on the Rise-from Mitotic Entry to Cytokinesis with Plk1. Dev Cell 2008;14:646-659.

-25 Subramanian R, Wilson-Kubalek EM, Arthur CP, Bick MJ, Campbell EA, Darst SA, Milligan RA, Kapoor TM: Insights into antiparallel microtubule crosslinking by PRC1, a conserved nonmotor microtubule binding protein. Cell 2010;142:433-443.

-26 Jiang W, Jimenez G, Wells NJ, Hope TJ, Wahl GM, Hunter T, Fukunaga R: PRC1: a human mitotic spindleassociated CDK substrate protein required for cytokinesis. Mol Cell 1998;2:877-885.

27 Zhu C, Jiang W: Cell cycle-dependent translocation of PRC1 on the spindle by Kif4 is essential for midzone formation and cytokinesis. Proc Natl Acad Sci U S A 2005;102:343-348.

28 Neef R, Gruneberg U, Kopajtich R, Li X, Nigg EA, Sillje H, Barr FA: Choice of Plk1 docking partners during mitosis and cytokinesis is controlled by the activation state of Cdk1. Nat Cell Biol 2007;9:436-444.

29 Petronczki M, Glotzer M, Kraut N, Peters JM: Polo-like kinase 1 triggers the initiation of cytokinesis in human cells by promoting recruitment of the RhoGEF Ect2 to the central spindle. Dev Cell 2007;12:713-725.

-30 Lowery DM, Clauser KR, Hjerrild M, Lim D, Alexander J, Kishi K, Ong SE, Gammeltoft S, Carr SA, Yaffe MB: Proteomic screen defines the Polo-box domain interactome and identifies Rock2 as a Plk1 substrate. EMBO J 2007;26:2262-2273.

-31 Niiya F, Xie X, Lee KS, Inoue H, Miki T: Inhibition of cyclin-dependent kinase 1 induces cytokinesis without chromosome segregation in an ECT2 and MgcRacGAP-dependent manner. J Biol Chem 2005;280:3650236509.

-32 Narumiya S, Yasuda S: Rho GTPases in animal cell mitosis. Curr Opin Cell Biol 2006;18:199-205.

-33 Caballe A, Martin-Serrano J: ESCRT machinery and cytokinesis: the road to daughter cell separation. Traffic 2011;12:1318-1326.

34 Gromley A, Yeaman C, Rosa J, Redick S, Chen CT, Mirabelle S, Guha M, Sillibourne J, Doxsey SJ: Centriolin anchoring of exocyst and SNARE complexes at the midbody is required for secretory-vesicle-mediated abscission. Cell 2005;123:75-87.

35 Goss JW, Toomre DK: Both daughter cells traffic and exocytose membrane at the cleavage furrow during mammalian cytokinesis. J Cell Biol 2008;181:1047-1054.

-36 Dhonukshe P, Baluska F, Schlicht M, Hlavacka A, Samaj J, Friml J, Gadella TW Jr: Endocytosis of cell surface material mediates cell plate formation during plant cytokinesis. Dev Cell 2006;10:137-150.

37 Wilson GM, Fielding AB, Simon GC, Yu X, Andrews PD, Hames RS, Frey AM, Peden AA, Gould GW, Prekeris R: The FIP3-Rab11 protein complex regulates recycling endosome targeting to the cleavage furrow during late cytokinesis. Mol Biol Cell 2005;16:849-860. 
-38 Chow CM, Neto H, Foucart C, Moore I: Rab-A2 and Rab-A3 GTPases define a trans-golgi endosomal membrane domain in Arabidopsis that contributes substantially to the cell plate. Plant Cell 2008;20:101-123.

39 Riggs B, Rothwell W, Mische S, Hickson GRX, Matheson J, Hays TS, Gould GW, Sullivan W: Actin cytoskeleton remodeling during early Drosophila furrow formation requires recycling endosomal components Nuclearfallout and Rab11. J Cell Biol 2003;163:143-154.

40 Horgan CP, McCaffrey MW: The dynamic Rab11-FIPs. Biochem Soc Trans 2009;37:1032-1036.

-41 Horgan CP, Walsh M, Zurawski TH, McCaffrey MW: Rab11-FIP3 localises to a Rab11-positive pericentrosomal compartment during interphase and to the cleavage furrow during cytokinesis. Biochem Biophys Res Commun 2004;319:83-94.

42 Collins LL, Simon G, Matheson J, Wu C, Miller MC, Otani T, Yu X, Hayashi S, Prekeris R, Gould GW: Rab11-FIP3 is a cell cycle-regulated phosphoprotein. BMC Cell Biol 2012;13:4.

43 Schweitzer JK, Sedgwick AE, D'Souza-Schorey C: ARF6-mediated endocytic recycling impacts cell movement, cell division and lipid homeostasis. Semin Cell Dev Biol 2011;22:39-47.

44 Fielding AB, Schonteich E, Matheson J, Wilson G, Yu X, Hickson GRX, Srivastava S, Baldwin SA, Prekeris R, Gould GW: Rab11-FIP3 and FIP4 interact with Arf6 and the exocyst to control membrane traffic in cytokinesis. EMBO J 2005;24:3389-3399.

-45 Douglas ME, Davies T, Joseph N, Mishima M: Aurora B and 14-3-3 coordinately regulate clustering of centralspindlin during cytokinesis. Curr Biol 2010;20:927-933.

46 Joseph N, Hutterer A, Poser I, Mishima M: ARF6 GTPase protects the post-mitotic midbody from 14-3-3-mediated disintegration. EMBO J 2012;31:2604-2614.

$\checkmark 47$ Kouranti I, Sachse M, Arouche N, Goud B, Echard A: Rab35 regulates an endocytic recycling pathway essential for the terminal steps of cytokinesis. Curr Biol 2006;16:1719-1725.

48 Sato M, Sato K, Liou W, Pant S, Harada A, Grant BD: Regulation of endocytic recycling by C. elegans Rab35 and its regulator RME-4, a coated-pit protein. EMBO J 2008;27:1183-1196.

49 Zhang J, Fonovic M, Suyama K, Bogyo M, Scott MP: Rab35 controls actin bundling by recruiting fascin as an effector protein. Science 2009;325:1250-1254.

50 Chua CEL, Lim YS, Tang BL: Rab35--a vesicular traffic-regulating small GTPase with actin modulating roles. FEBS Lett 2010;584:1-6.

51 Cao J, Albertson R, Riggs B, Field CM, Sullivan W: Nuf, a Rab11 effector, maintains cytokinetic furrow integrity by promoting local actin polymerization. J Cell Biol 2008;182:301-313.

52 Jing J, Tarbutton E, Wilson G, Prekeris R: Rab11-FIP3 is a Rab11-binding protein that regulates breast cancer cell motility by modulating the actin cytoskeleton. Eur J Cell Biol 2009;88:325-341.

53 Pirruccello M, De Camilli P: Inositol 5-phosphatases: insights from the Lowe syndrome protein OCRL. Trends Biochem Sci 2012;37:134-143.

54 Dambournet D, Machicoane M, Chesneau L, Sachse M, Rocancourt M, El Marjou A, Formstecher E, Salomon R, Goud B, Echard A: Rab35 GTPase and OCRL phosphatase remodel lipids and F-actin for successful cytokinesis. Nat Cell Biol 2011;13:981-988.

55 Field SJ, Madson N, Kerr ML, Galbraith KAA, Kennedy CE, Tahiliani M, Wilkins A, Cantley LC: PtdIns(4,5)P2 functions at the cleavage furrow during cytokinesis. Curr Biol 2005;15:1407-1412.

56 Polevoy G, Wei HC, Wong R, Szentpetery Z, Kim YJ, Goldbach P, Steinbach SK, Balla T, Brill JA: Dual roles for the Drosophila PI 4-kinase four wheel drive in localizing Rab11 during cytokinesis. J Cell Biol 2009;187:847858.

57 Kobayashi H, Fukuda M: Rab35 regulates Arf6 activity through centaurin- 32 (ACAP2) during neurite outgrowth. J Cell Sci 2012;125:2235-2243.

58 Chesneau L, Dambournet D, Machicoane M, Kouranti I, Fukuda M, Goud B, Echard A: An ARF6/Rab35 GTPase cascade for endocytic recycling and successful cytokinesis. Curr Biol 2012;22:147-153.

59 Thullberg M, Gad A, Le Guyader S, Strömblad S: Oncogenic H-Ras V12 promotes anchorage-independent cytokinesis in human fibroblasts. Proc Natl Acad Sci U S A 2007;104:20338-20343.

60 Tsujioka M, Yumura S, Inouye K, Patel H, Ueda M, Yonemura S: Talin couples the actomyosin cortex to the plasma membrane during rear retraction and cytokinesis. Proc Natl Acad Sci U S A 2012;109:12992-12997.

61 LaFlamme SE, Nieves B, Colello D, Reverte CG: Integrins as regulators of the mitotic machinery. Curr Opin Cell Biol 2008;20:576-582. 


\section{Cellular Physiology $\quad$ Cell Physiol Biochem 2012;30:1097-1108 and Biochemistry \begin{tabular}{l|l} 
DOI: 10.1159/000343301 & Published online: September 27, 2012 \\
\hline
\end{tabular}}

-62 Pellinen T, Tuomi S, Arjonen A, Wolf M, Edgren H, Meyer H, Grosse R, Kitzing T, Rantala JK, Kallioniemi O, Fässler R, Kallio M, Ivaska J: Integrin trafficking regulated by Rab21 is necessary for cytokinesis. Dev Cell 2008;15:371-385.

63 Högnäs G, Tuomi S, Veltel S, Mattila E, Murumägi A, Edgren H, Kallioniemi O, Ivaska J: Cytokinesis failure due to derailed integrin traffic induces aneuploidy and oncogenic transformation in vitro and in vivo. Oncogene 2012;31:3597-3606.

-64 He B, Guo W: The exocyst complex in polarized exocytosis. Curr Opin Cell Biol 2009;21:537-542.

65 Murthy M, Teodoro RO, Miller TP, Schwarz TL: Sec5, a member of the exocyst complex, mediates Drosophila embryo cellularization. Development 2010;137:2773-2783.

-66 Fendrych M, Synek L, Pecenková T, Toupalová H, Cole R, Drdová E, Nebesárová J, Sedinová M, Hála M, Fowler JE, Zársky V: The Arabidopsis exocyst complex is involved in cytokinesis and cell plate maturation. Plant Cell 2010;22:3053-3065.

67 Bodemann BO, White MA: Ral GTPases and cancer: linchpin support of the tumorigenic platform. Nat Rev Cancer 2008;8:133-140.

68 Chen XW, Inoue M, Hsu SC, Saltiel AR: RalA-exocyst-dependent recycling endosome trafficking is required for the completion of cytokinesis. J Biol Chem 2006;281:38609-38616.

69 Cascone I, Selimoglu R, Ozdemir C, Del Nery E, Yeaman C, White M, Camonis J: Distinct roles of RalA and RalB in the progression of cytokinesis are supported by distinct RalGEFs. EMBO J 2008;27:2375-2387.

70 Lowe M: Membrane transport: tethers and TRAPPs. Curr Biol 2000;10:R407-R409.

71 Brown FC, Pfeffer SR: An update on transport vesicle tethering. Mol Membr Biol 2010;27:457-461.

72 Sacher M, Kim YG, Lavie A, Oh BH, Segev N: The TRAPP complex: insights into its architecture and function. Traffic 2008;9:2032-2042.

73 Yu S, Liang Y: A trapper keeper for TRAPP, its structures and functions. Cell Mol Life Sci 2012;

74 Robinett CC, Giansanti MG, Gatti M, Fuller MT: TRAPPII is required for cleavage furrow ingression and localization of Rab11 in dividing male meiotic cells of Drosophila. J Cell Sci 2009;122:4526-4534.

75 Thellmann M, Rybak K, Thiele K, Wanner G, Assaad FF: Tethering factors required for cytokinesis in Arabidopsis. Plant Physiol 2010;154:720-732.

76 Montagnac G, Sibarita JB, Loubéry S, Daviet L, Romao M, Raposo G, Chavrier P: ARF6 Interacts with JIP4 to control a motor switch mechanism regulating endosome traffic in cytokinesis. Curr Biol 2009;19:184-195.

77 Südhof TC, Rothman JE: Membrane fusion: grappling with SNARE and SM proteins. Science 2009;323:474477.

78 Lauber MH, Waizenegger I, Steinmann T, Schwarz H, Mayer U, Hwang I, Lukowitz W, Jürgens G: The Arabidopsis KNOLLE protein is a cytokinesis-specific syntaxin. J Cell Biol 1997;139:1485-1493.

79 Waizenegger I, Lukowitz W, Assaad F, Schwarz H, Jürgens G, Mayer U: The Arabidopsis KNOLLE and KEULE genes interact to promote vesicle fusion during cytokinesis. Curr Biol 2000;10:1371-1374.

-80 Heese M, Gansel X, Sticher L, Wick P, Grebe M, Granier F, Jurgens G: Functional characterization of the KNOLLE-interacting t-SNARE AtSNAP33 and its role in plant cytokinesis. J Cell Biol 2001;155:239-249.

-81 Zheng H, Bednarek SY, Sanderfoot AA, Alonso J, Ecker JR, Raikhel NV: NPSN11 is a cell plate-associated SNARE protein that interacts with the syntaxin KNOLLE. Plant Physiol 2002;129:530-539.

82 Zhang L, Zhang H, Liu P, Hao H, Jin JB, Lin J: Arabidopsis R-SNARE proteins VAMP721 and VAMP722 are required for cell plate formation. PloS one 2011;6:e26129.

-83 Rancour DM, Dickey CE, Park S, Bednarek SY: Characterization of AtCDC48. Evidence for multiple membrane fusion mechanisms at the plane of cell division in plants. Plant Physiol 2002;130:1241-1253.

84 Low SH, Li X, Miura M, Kudo N, Quiñones B, Weimbs T: Syntaxin 2 and endobrevin are required for the terminal step of cytokinesis in mammalian cells. Dev Cell 2003;4:753-759.

$85 \mathrm{Xu} \mathrm{H}$, Brill JA, Hsien J, McBride R, Boulianne GL, Trimble WS: Syntaxin 5 is required for cytokinesis and spermatid differentiation in Drosophila. Dev Biol 2002;251:294-306.

86 Song SJ, Kim SJ, Song MS, Lim DS: Aurora B-mediated phosphorylation of RASSF1A maintains proper cytokinesis by recruiting Syntaxin16 to the midzone and midbody. Cancer Res 2009;69:8540-8544.

87 Neto H, Gould GW: The regulation of abscission by multi-protein complexes. J Cell Sci 2011;124:3199-3207.

88 Carlton JG, Caballe A, Agromayor M, Kloc M, Martin-Serrano J: ESCRT-III governs the Aurora B-mediated abscission checkpoint through CHMP4C. Science 2012;336:220-225.

89 Hurley JH, Hanson PI: Membrane budding and scission by the ESCRT machinery: it's all in the neck. Nat Rev Mol Cell Biol 2010;11:556-566. 
Tang: Membrane Traffic in Cytokinesis

-90 Peel S, Macheboeuf P, Martinelli N, Weissenhorn W: Divergent pathways lead to ESCRT-III-catalyzed membrane fission. Trends Biochem Sci 2011;36:199-210.

-91 Rusten TE, Vaccari T, Stenmark H: Shaping development with ESCRTs. Nat Cell Biol 2011;14:38-45.

$\$ 92$ Saksena S, Sun J, Chu T, Emr SD: ESCRTing proteins in the endocytic pathway. Trends Biochem Sci 2007;32:561-573.

$\$ 93$ Hill CP, Babst M: Structure and function of the membrane deformation AAA ATPase Vps4. Biochim Biophys Acta 2012;1823:172-181.

$\$ 94$ Carlton JG, Martin-Serrano J: Parallels between cytokinesis and retroviral budding: a role for the ESCRT machinery. Science 2007;316:1908-1912.

-95 Fabbro M, Zhou BB, Takahashi M, Sarcevic B, Lal P, Graham ME, Gabrielli BG, Robinson PJ, Nigg EA, Ono Y, Khanna KK: Cdk1/Erk2- and Plk1-dependent phosphorylation of a centrosome protein, Cep55, is required for its recruitment to midbody and cytokinesis. Dev Cell 2005;9:477-488.

-96 Lee HH, Elia N, Ghirlando R, Lippincott-Schwartz J, Hurley JH: Midbody targeting of the ESCRT machinery by a noncanonical coiled coil in CEP55. Science 2008;322:576-580.

$\$ 97$ Elia N, Sougrat R, Spurlin TA, Hurley JH, Lippincott-Schwartz J: Dynamics of endosomal sorting complex required for transport (ESCRT) machinery during cytokinesis and its role in abscission. Proc Natl Acad Sci USA 2011;108:4846-4851.

-98 Steigemann P, Wurzenberger C, Schmitz MHA, Held M, Guizetti J, Maar S, Gerlich DW: Aurora B-mediated abscission checkpoint protects against tetraploidization. Cell 2009;136:473-484.

-99 Guizetti J, Schermelleh L, Mäntler J, Maar S, Poser I, Leonhardt H, Müller-Reichert T, Gerlich DW: Cortical constriction during abscission involves helices of ESCRT-III-dependent filaments. Science 2011;331:16161620.

100 Hanson PI, Roth R, Lin Y, Heuser JE: Plasma membrane deformation by circular arrays of ESCRT-III protein filaments. J Cell Biol 2008;180:389-402.

101 Lata S, Schoehn G, Jain A, Pires R, Piehler J, Gottlinger HG, Weissenhorn W: Helical structures of ESCRT-III are disassembled by VPS4. Science 2008;321:1354-1357.

102 Bodon G, Chassefeyre R, Pernet-Gallay K, Martinelli N, Effantin G, Hulsik DL, Belly A, Goldberg Y, ChatellardCausse C, Blot B, Schoehn G, Weissenhorn W, Sadoul R: Charged multivesicular body protein 2B (CHMP2B) of the endosomal sorting complex required for transport-III (ESCRT-III) polymerizes into helical structures deforming the plasma membrane. J Biol Chem 2011;286:40276-40286.

103 Horgan CP, Hanscom SR, Kelly EE, McCaffrey MW: Tumor susceptibility gene 101 (TSG101) is a novel binding-partner for the class II Rab11-FIPs. PloS one 2012;7:e32030. 